\title{
BMJ Open Service users' experiences of contacting NHS patient medicines helpline services: a qualitative study
}

\author{
Matt Williams (D) , ${ }^{1}$ Abbie Jordan (D) , Jennifer Scott (i) , ${ }^{1}$ Matthew D Jones (i) ${ }^{1}$
}

\begin{abstract}
To cite: Williams $M$, Jordan A, Scott J, et al. Service users' experiences of contacting NHS patient medicines helpline services: a qualitative study. BMJ Open 2020;10:e036326. doi:10.1136/ bmjopen-2019-036326

- Prepublication history and additional material for this paper are available online. To view these files, please visit the journal online (http://dx.doi. org/10.1136/bmjopen-2019036326).
\end{abstract}

Received 11 December 2019 Revised 30 March 2020 Accepted 13 May 2020

Check for updates

(c) Author(s) (or their employer(s)) 2020. Re-use permitted under CC BY-NC. No commercial re-use. See rights and permissions. Published by BMJ.

${ }^{1}$ Department of Pharmacy \& Pharmacology, University of Bath, Bath, UK

${ }^{2}$ Psychology and Centre for Pain Research, University of Bath, Bath, UK

Correspondence to Dr Matthew D Jones; m.d.jones@bath.ac.uk

\section{ABSTRACT}

Objectives Patient medicines helpline services (PMHS) are available from some National Health Service (NHS) Trusts in the UK to provide medicines information to hospital patients and carers. To date, studies of PMHS have examined the views of service users via satisfaction surveys. This study used qualitative methods to explore service users' experiences of using a PMHS, including perceived benefits and areas for improvement.

Design Qualitative, using semi-structured interviews. Setting This study was conducted across seven NHS Trusts in England.

Participants Forty users of PMHS were individually interviewed over the telephone. Interviews were audiorecorded, transcribed verbatim and analysed using Braun and Clarke's inductive reflexive thematic analysis. Ethical approval was obtained before study commencement. Results Participants predominantly called a PMHS for themselves (82\%; carers: 18\%). Two main themes were generated. Theme 1: timeliness_-PMHS provide support during the uncertain transition of care period from hospital to home, when patients and carers often feel vulnerable because support is less available. PMHS met service users' needs for timely and easily accessible support, and quick resolution of their issues. PMHS could be improved with staffing beyond typical work week hours, and by having staff available to answer calls instead of using an answerphone. Theme 2: PMHS are best-placed to helpPMHS were perceived as best-placed to answer enquiries that arose from hospital care. Service users felt reassured from speaking to pharmacy professionals, and PMHS were perceived as the optimal service in terms of knowledge and expertise regarding medicines-related questions. However, several participants were initially unaware that their PMHS existed.

Conclusions PMHS are perceived to be a valuable means of accessing timely medicines-related support when patients and carers may be feeling particularly vulnerable. However, their availability and promotion could be improved. We recommend that providers of PMHS consider whether this is achievable, in order to better meet the needs of service users.

\section{BACKGROUND}

Many patients leave hospital with gaps in their knowledge about their medicines, ${ }^{1-6}$ and a sizeable number of patients subsequently experience medicines-related errors and

\section{Strengths and limitations of this study}

This is the first study to adopt an idiographic approach to exploring service users' experiences of using patient medicines helpline services.

- Participants were recruited from a geographically diverse range of National Health Service (NHS) Trusts $(n=7)$ across England.

- Providers of the services acted as gatekeepers to participants, which may have resulted in selection bias.

- The sample primarily comprised service users from acute NHS Trusts, and therefore could have been improved by additional service users from other trust types (ie, specialist, mental health, and community).

require support with medicines-related problems. ${ }^{7-14}$ Consequently, hospital discharge may be a confusing and/or risky period for patients who have recently experienced changes to their medicines.

Patient medicines helpline services (PMHS) have been set up at some National Health Service (NHS) Trusts in the UK with the aim of providing medicines-related support to recently discharged hospital patients and their carers. The first PMHS was set up in the UK in 1992, and a survey study conducted in 2017 reported that $52 \%$ of NHS Trusts provided a PMHS. ${ }^{15}$ Providing a PMHS accords with World Health Organisation policy, which states that offering information on medicines via medicines information (MI) centres, and providing public education about medicines, are essential interventions to promote the rational use of medicines. ${ }^{16}$

In line with healthcare quality improvement approaches, services are likely to be improved by seeking to understand the experiences and needs of service users. ${ }^{17}$ In order to ascertain service users' views and experiences of PMHS, quantitative satisfaction survey studies have been conducted, whereas qualitative studies have not. ${ }^{18}$ The results of such survey studies suggest that service users typically consider 
PMHS to be beneficial. ${ }^{18}$ For example, a recent systematic review found that satisfaction ratings are excellent, the advice received is reported to be usually followed, and users report several positive outcomes (eg, feeling reassured, and improved health). ${ }^{18}$ However, a limitation of survey studies is that surveys include questions that are important to the researcher, rather than allowing participants to provide in-depth information that is important to them. Relatedly, survey answer options do not permit participants to respond in-depth using their own words. To enable service users to provide a detailed consideration of how and why PMHS may be beneficial and how they could be improved, an idiographic approach is needed.

Whereas the nomothetic approach is considered useful for making generalisations about groups of individuals in order to make assumptions about populations, the idiographic approach is considered useful for exploring individuals' lived experiences of a phenomenon. ${ }^{19}$ Idiography is concerned with exploring the in-depth experiences of particular individuals in particular contexts, and qualitative methods are considered appropriate for collecting rich data in order to achieve this. ${ }^{19}$ Consequently, our study sought to address an important knowledge gap by being the first study to take an idiographic approach, and use qualitative methods, to explore service users' experiences of contacting a PMHS.

\section{Aim}

The aim of this novel qualitative study was to explore patients' and carers' experiences of using a PMHS, including their perceived benefits, and ways that they can be improved. Through learning about patients' and carers' experiences of PMHS, we aimed to suggest improvements to how PMHS are delivered. In particular, this study addressed the following research question: What are patients' and carers' experiences of using NHS patient medicines helpline services?

\section{METHOD}

\section{Study design}

The authors adopted the epistemological position of pragmatism, in order to develop recommendations for service improvement for the benefit of users of PMHS. Pragmatism uses appropriate methods for solving practical problems, with an emphasis on the usefulness of research. ${ }^{20}$ Pragmatism has become increasingly popular in health research, since its aim is to produce findings that are of benefit to service users. ${ }^{20-22}$

For transparency, the study authors comprise three university academics with PhDs (one man, two women) and one PhD student with an MSc (man). All study authors have an interest in pharmacy practice, health services research and/or health psychology. One author (MJ) has prior experience of managing a PMHS for an NHS Trust in England.

\section{Participants and recruitment}

Recruitment was conducted via seven NHS Trusts from different regions within England: four acute trusts, one mental health trust, one specialist trust and one community trust. Initially, four NHS Trusts were recruited, one of each type. Additional NHS Trusts of all types were subsequently recruited in order to ensure that our sample target was met, and to enhance the diversity of experiences included in the analysis. However, only three additional acute trusts agreed to take part. Pharmacy professionals who provided the PMHS at sites acted as gatekeepers to the recruitment of participants, with each site recruiting participants over a 6-month period.

Eligible participants were required to be either a patient, or a patient's non-professional carer, who recently used a PMHS provided by an NHS Trust within England for the purpose of seeking support regarding medicines. Participants were also required to be aged 16 years or older, fluent in English and available to participate in a telephone interview within 1 month of having used the PMHS. Participants were excluded if, in the pharmacy professional's judgement, taking part would likely cause distress to the service user. Pharmacy professionals were also required to exclude service users who stated they were (or were considering) making a report against the NHS Trust, and if the service user was a healthcare professional to the patient.

Invitations to participate in the study were sent from NHS Trusts to all helpline enquirers who agreed to receive study information at the end of their call to the PMHS. After reading the study participant information sheet, interested individuals opted in by contacting the research team via telephone or email in order to participate. Prior to participation, interested individuals were informed as to the purpose of the study and what participation entailed, including key ethical issues (eg, data storage and confidentiality). Interested individuals also had the opportunity to ask questions about the study.

Our estimated sample size was based on that of published qualitative studies of service users' experiences of healthcare services, and recommendations in literature. ${ }^{23}$ In relation to such guidance, we aimed to conduct 40 interviews. The sample size was not based on reaching data saturation. The concept of data saturation has been challenged as a means of identifying the appropriate number of participants to include in a study. ${ }^{24}$ For example, it has been suggested that data may never be truly saturated, since there could always be potential codes and themes to be identified. ${ }^{25}$

The first 40 individuals who contacted the study team and met the study eligibility criteria were recruited into the study. Prior to data collection, verbal informed consent was obtained from each participant via telephone, which is appropriate for low risk, telephone interview studies. ${ }^{26}$ 


\section{Box 1 Topics for the interviews with service users}

1. Why the patient/carer contacted the helpline service, including what their question or concern was, the perceived seriousness of the issue, whether they considered any other sources of medicines information, and their decision-making process for choosing to use the helpline service.

2. What the patient/carer found helpful and unhelpful about their experience of contacting the medicines helpline service.

3. What impact the patient's/carer's use of the service has had (eg, Was the advice followed? If so, what were the outcomes of this? If the advice was not followed, what were the reasons for this?).

4. Whether there were any self-perceived negative consequences of using the helpline service.

5. How the patient/carer felt about the medicines now, compared with before the helpline contact.

6. How the patient/carer felt about the hospital and National Health Service Trust now, compared with before the helpline contact.

7. What the patient/carer would have done had the helpline service not been available, and why.

8. Whether the patient/carer sought any other sources of medicinesrelated information or support following their use of the helpline service, and if so, why.

\section{Data collection}

Semi-structured interviews were chosen as the data collection method in order to provide flexibility through the use of probes and unplanned questions. This increased the potential for producing richer data compared with other approaches that were considered, such as a qualitative survey. ${ }^{23}$ Data were collected via telephone, enabling participants throughout England to be easily interviewed. Evidence suggests that telephone interviews can lead to rich data, provided that interviewers ensure that participants' needs are understood and respected.$^{27}{ }^{28}$ Consequently, care was taken to ensure that participants were comfortable being interviewed over the telephone, and that they also felt able to pause the interview at any time and to ask for clarification. Each participant was interviewed once.

During the same telephone call as the interview, but before the interview was conducted, the following background information was collected from participants: name of the NHS Trust contacted, date of the PMHS contact, and whether they had previously used a PMHS. Patients were also asked whether they were an inpatient or outpatient for their recent period of care, and the number of medicines they were prescribed at the time of the PMHS contact. Carers were also asked their relationship to the patient who the PMHS contact was regarding.

Separate interview schedules were developed for patients and carers (see online supplementary file 1 for the interview schedules). Box 1 provides a summary of the interview topics (eg, what the patient/carer found helpful and unhelpful about their experience of contacting the PMHS). The interview schedules were broadly similar, although, for ethical reasons, the carer version did not contain questions that would have resulted in them providing personal information about the individual in their care. The aim of the interview with carers was to explore whether the PMHS met their needs as a carer seeking information. Both schedules comprised openended questions, and were developed in accordance with established conventions for semi-structured interviewing. ${ }^{23}$ 29-31

During data collection, the interview schedules served as flexible guides for interviews, enabling participants to discuss aspects of their experiences of using a PMHS that were important to them.

During the same telephone call as the interview, but after their interview had been conducted, the following background data were collected from each participant: age, gender, ethnicity, and current occupational status.

All interviews were conducted by a trained interviewer (MW), audio-recorded, and transcribed verbatim (MW).

\section{Data analysis}

Braun and Clarke's inductive reflexive thematic analysis (TA) was used to analyse the qualitative interview data. ${ }^{3233} \mathrm{TA}$ is a systematic, rigorous and transparent technique for organising, describing and interpreting data, which has been used within health research to explore patients' experiences of healthcare services. ${ }^{34-36}$ Braun and Clarke's TA was chosen instead of other thematic methods, since it provides a straight-forward step-bystep process for conducting a thorough and transparent analysis.

Analysis involved the following stages, as outlined by Braun and Clarke: familiarisation with the data, generating initial codes, developing themes, reviewing themes, defining and naming themes, and writing the analysis. ${ }^{23} 32$ Individual interview transcripts were uploaded into NVivo V.12, ${ }^{37}$ which was used for generating initial codes and developing themes. The only deviation to the TA stages was that iterative categorisation (IC) was used in place of the reviewing themes stage. ${ }^{38}$ The choice to use IC was made in order to increase transparency and rigour. IC is also a systematic, rigorous and transparent technique, which can be used to support a range of analytical techniques, including TA. ${ }^{38}$ IC leaves a clear audit trail, which provides a route back to the coded data (see Neale ${ }^{38}$ for further details).

\section{Patient and public involvement}

The study design and documents (participant information sheet and interview schedules) were reviewed by six members of the public who were either recent hospital patients or carers. Refinements were made based on their feedback. Patients/the public were not involved in the recruitment of participants, nor dissemination of findings.

\section{Establishing quality in qualitative research}

Yardley's criteria for demonstrating the quality of qualitative research were met. ${ }^{39}$ For sensitivity to context, previous literature was reviewed in preparation for the study, and 
we endeavoured to recruit participants from several different NHS Trusts. For commitment and rigour, TA and IC stages were followed, including Braun and Clarke's 15-point guidelines on conducting $\mathrm{TA},{ }^{23}$ and a 'paper trail' approach was used. Also, credibility checks were conducted, where each stage of the analysis was checked by another member of the research team to verify that the identified codes and themes were appropriate. Additionally, the Consolidated Criteria for Reporting Qualitative Research and the Standards for Reporting Qualitative Research were followed. ${ }^{40}{ }^{41}$ For coherence and transparency, the study results are grounded in example quotations from the raw data. A reflective diary was used throughout the process of data collection and analysis to record thoughts about each interview, contextual features that may have influenced interviews, and/or any ways that interviews could have been improved in order to enhance subsequent interviews. Additionally, the authors have disclosed their positions regarding the research topic. For impact and importance, the study findings were used to develop recommendations for improving the provision of PMHS.

\section{RESULTS}

\section{Participant characteristics}

Table 1 provides an overview of participant characteristics (see online supplementary file 2 for anonymised information regarding each participant). Participants were predominantly female, elderly, had used a PMHS regarding themselves, and had used a PMHS that was based at an acute NHS Trust. Table 2 provides an overview of the types of enquiries that participants made to the PMHS.

\section{Interview duration}

Interview duration ranged from 12 to 66 minutes (mean= 25 minutes).

\section{Overview of themes}

Two main themes were generated from the analysis: timeliness, and PMHS are best-placed to help. Timeliness identifies that service users often feel vulnerable after discharge from secondary care, and that service users want quick access to support when they need it, from pharmacy professionals who are available to help them. This is what PMHS have the potential to provide, although their availability could be improved. PMHS are best-placed to help reveals that PMHS may reduce the burden on other healthcare services, and that PMHS are considered to be the best place to access medicines-related support pertaining to hospital care, from pharmacy professionals with expert knowledge. Pharmacy professionals were considered to have positive personal qualities that helped to reassure service users. However, although PMHS are considered best-placed to help, service users' awareness of the existence of PMHS could be improved.
Table 1 Participant characteristics $(n=40)$

$\mathrm{n}(\%)$, or mean years (SD; range)

\begin{tabular}{|c|c|}
\hline Characteristic & (SD; range) \\
\hline \multicolumn{2}{|l|}{ Type of enquirer } \\
\hline Patient, calling for self & $33(82.5)$ \\
\hline Carer/calling on behalf of patient & $7(17.5)$ \\
\hline \multicolumn{2}{|l|}{ Type of patient ${ }^{\star}$} \\
\hline Recent inpatient & $17(51.5)$ \\
\hline Recent outpatient & $12(36.4)$ \\
\hline Former patient & $4(12.1)$ \\
\hline \multicolumn{2}{|l|}{ Type of carer† } \\
\hline Spouse or partner of patient & $5(71.4)$ \\
\hline Parent of patient & $1(14.3)$ \\
\hline Son or daughter of patient & $1(14.3)$ \\
\hline \multicolumn{2}{|c|}{ Number of medicines currently prescribed ${ }^{\star}$} \\
\hline $0-4$ & $11(33.3)$ \\
\hline $5-9$ & $19(57.6)$ \\
\hline 10 or more & $3(9.1)$ \\
\hline \multicolumn{2}{|l|}{ Gender of enquirer } \\
\hline Male & $17(42)$ \\
\hline Female & $23(58)$ \\
\hline Age of enquirer (years) & $68(9.87 ; 44-85)$ \\
\hline \multicolumn{2}{|l|}{ Ethnicity of enquirer } \\
\hline White or White British & $38(95)$ \\
\hline Asian or Asian British & $1(2.5)$ \\
\hline Mixed race & $1(2.5)$ \\
\hline \multicolumn{2}{|l|}{ Occupational status of enquirer } \\
\hline Retired & $30(75)$ \\
\hline Employed & $4(10)$ \\
\hline Unemployed & $4(10)$ \\
\hline Carer and/or homemaker & $2(5)$ \\
\hline \multicolumn{2}{|l|}{ Has enquirer used a PMHS in the past? } \\
\hline No & $34(85)$ \\
\hline Yes & $6(15)$ \\
\hline \multicolumn{2}{|l|}{ NHS Trust where PMHS was used } \\
\hline Acute 1 & $23(57.5)$ \\
\hline Acute 2 & $6(15)$ \\
\hline Acute 3 & $6(15)$ \\
\hline Acute 4 & $3(7.5)$ \\
\hline Mental health & $1(2.5)$ \\
\hline Specialist & $1(2.5)$ \\
\hline Community & $0(0)$ \\
\hline
\end{tabular}

*Data collected only from participants who were patients. †Data collected only from participants who were carers. NHS, National Health Service; PMHS, patient medicines helpline service.

\section{Theme 1: timeliness}

Vulnerable after discharge

Participants described feeling vulnerable after leaving hospital, and in need of support during this transition of 


\begin{tabular}{ll}
\hline $\begin{array}{l}\text { Table } 2 \\
(\mathrm{n}=40)\end{array}$ & Types of enquiries made by study participants \\
\hline Enquiry type & $\mathbf{n}(\%)$ \\
\hline Administration or dosage & $10(25)$ \\
\hline Interaction & $9(22.5)$ \\
Supply & $7(17.5)$ \\
Medicines-related error & $6(15)$ \\
Side effects & $6(15)$ \\
Storage & $2(5)$ \\
\hline
\end{tabular}

*Incorrect medicine prescribed $(n=3)$; missing medication $(n=2)$; discharge paperwork not sent to primary care, causing a delay to receive medication $(n=1)$.

care period. Reasons for feeling vulnerable after leaving hospital included being in recovery, feeling isolated, being house-bound, experiencing a medicines-related error (eg, a missing medication), being discharged with multiple medicines and feeling confused, and realising that they had not asked important questions during discharge. The PMHS was perceived to fulfil this important service gap.

If you've been discharged from hospital, for instance, you're given a bunch of medicines, it's explained to you, and perhaps you don't absorb it all completely ... It probably just doesn't quite go in until you come home ... and then you think 'Ah. Perhaps I should've asked this question'. In which case, if you've got something like this helpline, it's invaluable. (P11, male, patient)

\section{Accessing help}

Pertaining to feeling vulnerable after leaving hospital, participants perceived the situation as stressful and spoke of the need for immediate help with regards to medication advice. In order to reduce this stress, it was therefore important to be able to access support quickly (ie, no answerphone or additional buttons to press to get through), and to also have the situation resolved as soon as possible. This is what the PMHS typically enabled.

I was relieved, actually, to have somebody to talk to immediately that could help me within a short space of time. (P5, female, patient)

Participants spoke of the importance of the method of accessing the PMHS, and that the telephone was vital for accessing the service quickly, compared with accessing the service via email. Access methods were often described in relation to participants' perceived severity of the situation (ie, email would be useful for situations where help was not needed immediately).

I think it depends on the urgency of the situation ... Because of this situation, [telephone access] was great. It was immediate ... but if it wasn't a vital thing, then yes ... I could just email it through thinking 'I don't even need it today, this minute, but in the next couple of days would be helpful.' (P32, female, carer)

Relatedly, some participants commented that potential access options, such as online chat or a mobile phone app, would increase their stress.

I'm not that keen on technology. At a time when I felt really stressed out, I would've had an added stressor, having to work out how to do it. So, for me, it's very comforting, because I'm very familiar with the telephone [laughs]. (P10, female, patient)

However, participants felt that having more than one method of accessing support is useful, such as telephone and email. Several participants considered the access options of email, online chat, and mobile phone app to likely be preferable for younger service users.

\section{Availability of help}

Participants described how contacting the PMHS was likely to lead to a quicker resolution in comparison to other sources of support (eg, their general practitioner (GP), a local pharmacy, NHS 111, or another hospital contact). This was another reason why participants typically contacted the PMHS in the first instance.

I was waiting to hear back from the surgery, because I left it with the receptionist at the surgery ... But actually, I only got a call from the surgery this morning. And this was resolved [by the PMHS], you know, last week. (P16, female, patient)

Although most participants described their PMHS as timely, some were concerned about needing the service when it was unavailable (eg, evenings and weekends, to support patients who get discharged out-of-hours and people who are unable to contact the service during typical work hours).

Seven days a week would improve it. If you were discharged on the Friday night, being in the situation I was in, I would've been very concerned. (P9, female, patient)

Additionally, only one participant had a negative experience of contacting a PMHS, when they contacted the service for a second time. Here, the helpline team were not available to take the call. The participant left a message on the PMHS answerphone and was not called back.

I'm wondering if $\ldots$ a vulnerable patient was calling hoping to get some kind of reassurance, and left a message and they weren't called back, they would mistrust this service. (P6, female, patient)

\section{Theme 2: PMHS are best-placed to help}

Reduced burden upon other services

Participants considered their PMHS to be best-placed to help for several reasons. Primarily, participants spoke of the importance of returning to the place where they 
recently received care, rather than seeking advice elsewhere. Many participants felt that they would contact the hospital anyway, had the PMHS not existed.

As far as I was concerned. I'd just left the hospital, so I reckoned they [PMHS] would know. (P28, female, patient)

There was recognition that contacting the PMHS could reduce the burden on other healthcare services, or that queries may have gone unasked, since some participants described not wanting to burden other healthcare services. PMHS providers were perceived as having more time to answer queries compared with other healthcare professionals, particularly hospital consultants and GPs.

Hospitals and doctors are extremely busy, and some of the queries you might have might be very trivial, and take up time, which is not the best use of the medical practitioners' time. Some of those issues, if you can deal with a call to this helpline, then I think it's in everybody's best interest. (P31, male, patient)

\section{Source of expertise}

Participants spoke of the PMHS having the knowledge and resources to deal with enquiries that other healthcare professionals would not necessarily have (eg, access to medical records; an overview of their multiple health conditions and medicines regimen).

There's no point ringing up the doctor. Because they aren't specialised in all this treatment, you know. So that's why we rang the [PMHS]. (P1, female, carer)

Relatedly, participants described the benefit of speaking to a pharmacy professional regarding their medicines, since pharmacists are experts about medication and their advice can be trusted. Participants often described this as providing them with the reassurance needed to take their medicines as advised, particularly when taking multiple medicines, when the potential for mistakes is increased.

To make sure that whatever you're proposing to do has at least been under the eye of a pharmacist, makes you feel reassured that you're not doing anything that you shouldn't. (P21, male, patient)

\section{Positive personal qualities}

Participants also spoke of helpline staff as having positive personal qualities, which were important for providing them with reassurance at a time when they felt anxious. Several participants compared their positive experience with the helpline staff to less positive experiences with other healthcare professionals (eg, their GP). Positive personal qualities of helpline staff included being professional, calm, compassionate, down to earth, having good listening and communication skills, being knowledgeable and confident, being thorough, going above and beyond what they wanted, not being dismissive, and working with the patient to devise a plan to support them.
The person who I dealt with, she listened, she was compassionate, she normalised how I was feeling, and then in order to help alleviate the distress that I felt she made a plan that would reduce the distress that I was feeling. And it was a really really positive experience. (P37, male, patient)

\section{Helpful but hidden}

Although PMHS were considered best-placed to help, awareness of the services were sometimes poor. A number of participants described how they were not initially aware that their PMHS existed (eg, they called the hospital and were transferred to the PMHS). There was recognition that PMHS should be promoted more, since they are considered beneficial and could help a greater number of patients.

I wasn't aware it was available ... So I think the more that they can let people know that the service is available, the better. (P36, female, carer)

Suggestions for improving the promotion of PMHS included pharmacy professionals visiting wards to tell patients about it, putting posters up around the hospital and in the local area (GP surgeries, local pharmacies), and advertising within discharge summaries. However, one participant struggled to find the contact details within their discharge summary, and was initially unsure what the service provided because the promotion was unclear.

Almost put a bit more higher priority ... Because it was buried along in page three or five. I wouldn't have known how I could use that service, or if it was a priority I could use them, or whether I should try other routes before I use them. (P32, female, carer)

\section{DISCUSSION}

This study explored forty service users' experiences of using an NHS PMHS. Two themes were identified during the analysis: timeliness, and PMHS are best-placed to help. The findings illustrate how PMHS meet patients' and carers' needs for timely and easily accessible support, and for enquiries to be quickly resolved. However, PMHS may not always be considered a timely source of support, since the service is not available all the time. PMHS could therefore be improved by being available during evenings and at weekends. Additionally, providing a PMHS with an answerphone will mean that service users will experience a delay to receive help, and there may be a risk that messages are missed. PMHS were perceived to be uniquely placed to answer medication queries that arose from hospital care, and were more positively viewed as approachable and valuable when compared with other sources, such as GPs. However, several participants were initially unaware that the service existed, and so, increasing the promotion of PMHS would ensure that more patients have access to timely help when it is needed. Relatedly, increasing the 
promotion of PMHS will only be useful if the promotional materials are clear as to who the service is for, and what the service provides.

Our findings accord with those of a recent systematic review and a literature review that examined the evidence regarding the effectiveness of MI services for patients and the general public, both within the UK and internationally. ${ }^{18} 42$ Based on survey study findings, the systematic review concluded that such services are typically perceived positively by service users (eg, satisfaction ratings are excellent), and users report several positive outcomes such as feeling reassured and improved health. ${ }^{18}$ Our qualitative study found that PMHS provide reassurance to service users during the transition of care period when service users may be feeling particularly vulnerable. Their anxieties were alleviated by having quick access to an expert who had the skills to address their enquiries efficiently and compassionately.

Our findings also are consistent with two survey studies examining the provision of PMHS in the UK. ${ }^{15} 43$ The most recent of these was conducted in 2017, and surveyed all NHS Trusts in England in order to examine whether Royal Pharmaceutical Society endorsed national standards for providing a PMHS were being met. ${ }^{15} 44$ This survey identified that both the availability and promotion of PMHS were below standard. For example, out of 117 NHS Trusts that provided a PMHS, only $57 \%$ reported that their PMHS was available for 8 or more hours per day, and only 7\% reported that their PMHS was available out-ofhours, such as during evenings and weekends. Additionally, only $40 \%$ of NHS Trusts used promotional material describing PMHS access times and the types of enquiries that patients/carers can make. Under-promotion was also identified as an issue in a recently conducted qualitative study exploring 34 pharmacy professionals' perceptions of providing PMHS. ${ }^{45}$ Under-promotion was perceived by pharmacy professionals as a reason why PMHS are underused. Additionally, some pharmacy professionals described how their PMHS is under-promoted for fear of not being able to cope with the demand due to lack of resources to adequately deliver the service. Promotion of PMHS is important because if patients do not know that the service exists, they cannot use it, thus the opportunity to resolve medicines-related issues may be missed. This may result in harm to patients. An evaluation of 500 calls to one PMHS at an acute NHS Trust found that $48 \%$ of issues may have resulted in patient harm had professional information from the helpline not been available. ${ }^{46}$

\section{Recommendations for practice}

Study findings suggest that, to better meet the needs of service users, the provision of PMHS could be improved by extending their opening hours so that they are available during evenings and weekends. Providers should also ensure that helpline staff are available to answer the telephone rather than using answerphones. The promotion of the service could be improved to increase knowledge of the service among patients and carers. Such promotion could include ward pharmacists telling their patients and patients' carers about the PMHS during ward rounds, and by advertising the PMHS clearly in patients' copies of their discharge summaries. However, we appreciate that the above recommendations may be challenging since PMHS are often established without funding and are often provided within a resource-limited context. ${ }^{43} 45$ Because the findings described in the present study and in a recently conducted systematic review suggest that PMHS can have several benefits for patients, ${ }^{18}$ budget holders/commissioners should consider whether they should fund new PMHS. This is important, since a survey study conducted in 2017 reported that only $52 \%$ of NHS Trusts provided a PMHS. ${ }^{15}$

\section{Recommendations for future research}

Future research is needed to better understand the needs of patients and carers when contacting a PMHS, particularly pertaining to service availability, methods of access, and promotion. One option could be to conduct a large, prospective, multi-site mixed methods survey, with enquirers of all ages, in order to enhance the generalisability of the findings. Another option could be to conduct a discreet choice experiment in order to elicit potential service users' preferences regarding the provision of PMHS, such as the availability, access and promotion of the service. Further research is also needed to explore the experiences of patients and carers who have problems or queries regarding medicines following hospital discharge, yet do not contact their NHS Trust's PMHS. This may result in additional recommendations to improve the awareness and use of PMHS.

\section{Strengths and limitations}

This is the first study to take an idiographic approach to exploring service users' perceptions of PMHS, thereby providing rich and contextualised accounts of PMHS use that have resulted in recommendations for service improvement and future research endeavours. Service users were recruited from seven NHS Trusts from different regions within England in order to include a broad range of experiences of PMHS use. Additionally, consideration was made throughout the study to enhance the validity and trustworthiness of the findings. However, providers of the services acted as gatekeepers to participants, which may have resulted in selection bias. Furthermore, the sample predominantly comprised service users from acute NHS Trusts, and therefore could have been improved by the addition of service users from other NHS Trust types (ie, mental health, specialist, and community NHS Trusts). Finally, the sample may also be limited since participants had already chosen to contact a PMHS, and may therefore be likely to hold positive views about telephone helplines.

\section{CONCLUSION}

PMHS are seen as a valuable means of easily accessing timely medicines-related support during a transfer of care 
period, when patients and carers may be feeling particularly vulnerable. PMHS were perceived as best-placed to answer enquiries that arose from hospital care. PMHS were also perceived as the optimal service in terms of knowledge and expertise with regard to answering questions about medications. However, the availability and promotion of PMHS could be improved. We recommend that providers of PMHS consider whether this is achievable, in order to better meet the needs of service users.

Twitter Abbie Jordan @drabbiejordan, Jennifer Scott @JScottUoB and Matthew D Jones@MatthewJonesUoB

Acknowledgements We would like to thank the pharmacy professionals from the seven NHS Trusts who supported the study by being participant identification sites, and the patients and carers who took the time to participate in this study.

Contributors MW designed the study, collected all data, conducted the analyses and drafted the manuscript. AJ provided advice regarding study design, including expertise in qualitative methods and read, provided feedback and approved the final manuscript. JS provided advice regarding study design and read, provided feedback and approved the final manuscript. MJ provided advice regarding study design and read, provided feedback and approved the final manuscript.

Funding The lead author was funded by a graduate school scholarship provided by the University of Bath. The funder had no role in the study design, the collection, analysis and interpretation of the data, the writing of the report and the decision to submit the article for publication.

Competing interests None declared.

Patient and public involvement Patients and/or the public were involved in the design, or conduct, or reporting, or dissemination plans of this research. Refer to the Method section for further details.

Patient consent for publication Not required.

Ethics approval This study was reviewed and approved by the London - Brighton \& Sussex Research Ethics Committee, and the NHS Health Research Authority (IRAS ID: 233726). The study also received ethical clearance through the Research Ethics Approval Committee for Health of the University of Bath.

Provenance and peer review Not commissioned; externally peer reviewed.

Data availability statement Anonymised transcripts and datasets are available from the University of Bath Research Data Archive.

Open access This is an open access article distributed in accordance with the Creative Commons Attribution Non Commercial (CC BY-NC 4.0) license, which permits others to distribute, remix, adapt, build upon this work non-commercially, and license their derivative works on different terms, provided the original work is properly cited, appropriate credit is given, any changes made indicated, and the use is non-commercial. See: http://creativecommons.org/licenses/by-nc/4.0/.

\section{ORCID iDs}

Matt Williams http://orcid.org/0000-0002-9122-1858

Abbie Jordan http://orcid.org/0000-0003-1595-5574

Jennifer Scott http://orcid.org/0000-0002-4920-0914

Matthew D Jones http://orcid.org/0000-0002-2617-4098

\section{REFERENCES}

1 Care Quality Commission. 2015 Adult inpatient survey. statistical release. London, UK: Care Quality Commission, 2016.

2 Baker D, Roberts DE, Newcombe RG, et al. Evaluation of drug information for cardiology patients. Br J Clin Pharmacol 1991;31:525-31.

3 Knight DA, Thompson D, Mathie E, et al. 'Seamless care? just a list would have helped!' older people and their carer's experiences of support with medication on discharge home from hospital. Health Expect 2013;16:277-91.

4 Holloway A. Patient knowledge and information concerning medication on discharge from hospital. J Adv Nurs 1996;24:1169-74.

5 Pullar T, Roach P, Mellor EJ, et al. Patients' knowledge concerning their medications on discharge from hospital. J Clin Pharm Ther 1989;14:57-9.
6 Elson R, Cook H, Blenkinsopp A. Patients' knowledge of new medicines after discharge from Hospital: what are the effects of hospital-based discharge counseling and communitybased medicines use reviews (MURs)? Res Social Adm Pharm 2017;13:628-33.

7 Perren A, Previsdomini M, Cerutti B, et al. Omitted and unjustified medications in the discharge summary. Qual Saf Health Care 2009;18:205-8

8 Aldhwaihi K, Schifano F, Pezzolesi C, et al. A systematic review of the nature of dispensing errors in hospital pharmacies. Integr Pharm Res Pract 2016;5:1-10.

9 Marvin V, Vaughan L, Joshua A, et al. Medication-Related problems after discharge from acute care: a telephone follow-up pilot survey. Eur J Hosp Pharm 2012;19:112.2-112.

10 Williams $\mathrm{H}$, Edwards $\mathrm{A}$, Hibbert $\mathrm{P}$, et al. Harms from discharge to primary care: mixed methods analysis of incident reports. $\mathrm{Br} J \mathrm{Gen}$ Pract 2015;65:e829-37.

11 Davies EC, Green CF, Mottram DR, et al. Emergency re-admissions to hospital due to adverse drug reactions within 1 year of the index admission. Br J Clin Pharmacol 2010;70:749-55.

12 Eijsbroek H, Howell DCJ, Smith F, et al. Medication issues experienced by patients and carers after discharge from the intensive care unit. J Crit Care 2013;28:46-50.

13 Forster AJ, Murff HJ, Peterson JF, et al. The incidence and severity of adverse events affecting patients after discharge from the hospital. Ann Intern Med 2003;138:161-7.

14 Mackridge AJ, Rodgers R, Lee D, et al. Cross-sectional survey of patients' need for information and support with medicines after discharge from hospital. Int J Pharm Pract 2018;26:433-41.

15 Williams M, Jordan A, Scott J, et al. Operating a patient medicines helpline: a survey study exploring current practice in England using the RE-AIM evaluation framework. BMC Health Serv Res 2018;18:868.

16 World Health Organisation. Policy Perspectives on Medicines. In: Promoting rational use of medicines: core components. Geneva: Organisation WH, 2002.

17 NHS Institute for Innovation and Improvement. ExperienceBased design: using patient and staff experience to design better healthcare services.Aldridge, UK: new Audience limited, 2009. Available: https://www.england.nhs.uk/improvement-hub/ publication/experience-based-design-using-patient-and-staffexperience-to-design-better-healthcare-services-guide-and-tools/ [Accessed 7 Nov 2018].

18 Williams M, Jordan A, Scott J, et al. A systematic review examining the effectiveness of medicines information services for patients and the general public. Int J Pharm Pract 2020;28:26-40.

19 Smith JA, Flowers P, Larkin M. Interpretative phenomenological analsyis: theory, method, and research. London: Sage Publications Ltd, 2009.

20 Yvonne Feilzer M, Feilzer MY. Doing mixed methods research pragmatically: implications for the rediscovery of pragmatism as a research paradigm. J Mix Methods Res 2010;4:6-16.

21 Bishop FL. Using mixed methods research designs in health psychology: an illustrated discussion from a pragmatist perspective. Br J Health Psychol 2015;20:5-20.

22 Cornish F, Gillespie A. A pragmatist approach to the problem of knowledge in health psychology. J Health Psychol 2009;14:800-9.

23 Braun V, Clarke V, Research SQ. A practical guide for beginners. London, UK: Sage Publications Ltd, 2013.

24 O'Reilly M, Parker N. 'Unsatisfactory saturation': a critical exploration of the notion of saturated sample sizes in qualitative research. Qualitative Research 2013;13:190-7.

25 Wray N, Markovic M, Manderson L. "Researcher saturation": the impact of data triangulation and intensive-research practices on the researcher and qualitative research process. Qual Health Res 2007;17:1392-402.

26 The British Psychological Society. Code of human research ethics,Leicester, UK, 2010. Available: http://www.bps.org.uk/sites/ default/files/documents/code_of_human_research_ethics.pdf [Accessed 14 Apr 2017].

27 Ward K, Gott M, Hoare K. Participants' views of telephone interviews within a grounded theory study. J Adv Nurs 2015;71:2775-85.

28 Trier-Bieniek A. Framing the telephone interview as a participantcentred tool for qualitative research: a methodological discussion. Qualitative Research 2012;12:630-44.

29 Smith JA. Semi-structured interviewing and qualitative analysis. In: Rethinking methods in psychology. London, UK: Sage Publications Ltd, 1995: 9-26.

30 Willig C. Semi-structured interviewing. In: Introducing qualitative research in psychology. Second edn. Berkshire,England: Open University Press, 2008. 
31 King N, Horrocks C. Interviews in qualitative research. London: Sage Publications Ltd, 2010.

32 Braun V, Clarke V. Using thematic analysis in psychology. Qual Res Psychol 2006:3:77-101.

33 Clarke V, Braun V, Terry G, et al. Thematic analysis. In: Handbook of research methods in health and social sciences. Singapore: Springer, 2019: 843-60.

34 Dodd E, Cheston R, Cullum S, et al. Primary care-led dementia diagnosis services in South Gloucestershire: themes from people and families living with dementia and health care professionals. Dementia 2016;15:1586-604

35 Boyle E, Saunders R, Drury V. A qualitative study of patient experiences of type 2 diabetes care delivered comparatively by general practice nurses and medical practitioners. J Clin Nurs 2016;25:1977-86.

36 Murphy AL, Gardner DM, Jacobs LM. The patient experience in a community pharmacy mental illness and addictions program. Can Pharm J 2019;152:186-92.

37 N Vivo. NVivo qualitative data analysis software. Version 12. QSR international Pty LTD, 2018.

38 Neale J. Iterative categorization (IC): a systematic technique for analysing qualitative data. Addiction 2016;111:1096-106.
39 Yardley L. Dilemmas in qualitative health research. Psychol Health 2000:15:215-28.

40 Tong A, Sainsbury P, Craig J. Consolidated criteria for reporting qualitative research (COREQ): a 32-item checklist for interviews and focus groups. Int J Qual Health Care 2007;19:349-57.

41 O'Brien BC, Harris IB, Beckman TJ, et al. Standards for reporting qualitative research: a synthesis of recommendations. Acad Med 2014;89:1245-51.

42 Rutter J, Rutter P. Impact of pharmacy medicine information service advice on clinician and patient outcomes: an overview. Health Info Libr J 2019;36:299-317.

43 Raynor DK, Sharp JA, Rattenbury H, et al. Medicine information help lines: a survey of hospital pharmacy-based services in the UK and their conformity with guidelines. Ann Pharmacother 2000;34:106-11.

44 Wills S. Medicines helplines for hospital patients: national standards. UK: Royal Pharmaceutical Society, 2014.

45 Williams M, Jordan A, Scott J, et al. Pharmacy professionals' experiences and perceptions of providing NHS patient medicines helpline services: a qualitative study. BMC Health Serv Res 2020;20.

46 Marvin V, Park C, Vaughan L, et al. Phone calls to a hospital medicines information helpline: analysis of queries from members of the public and assessment of potential for harm from their medicines. Int J Pharm Pract 2011;19:115-22. 